\title{
Prevalence of overweight and obesity in preschool children in Thessaloniki, Greece
}

\author{
Maria Hassapidou, ${ }^{1}$ Efstratia Daskalou, ${ }^{1}$ Fotini Tsofliou, ${ }^{2}$ Konstantinos Tziomalos, ${ }^{3}$ \\ Anastasia Paschaleri, ${ }^{1}$ Ioannis Pagkalos, ${ }^{4}$ Themistoklis Tzotzas ${ }^{5}$
}

\begin{abstract}
${ }^{1}$ Department of Nutrition \& Dietetics, Alexander Technological Educational Institute of Thessaloniki, Sindos, Thessaloniki, Greece; ${ }^{2}$ Faculty of Health \& Social Sciences, Royal London House, Bournemouth University, Bournemouth, UK; ${ }^{3}$ First Propedeutic Department of Internal Medicine, Medical School, Aristotle University of Thessaloniki, AHEPA Hospital, ${ }^{4}$ Department of Electrical \& Computer Engineering, Aristotle University of Thessaloniki, ${ }^{5}$ Department of Endocrinology, Diabetes \& Metabolism, "Agios Pavlos" Hospital, Thessaloniki; Greece
\end{abstract}

\begin{abstract}
OBJECTIVE: Data on obesity in preschoolers are scarce in Greece, a country particularly affected by the obesity epidemic. The present study aimed to assess overweight and obesity prevalence of preschoolers in Thessaloniki, Greece, by using three different standards for defining childhood overweight and obesity. DESIGN: One thousand two hundred and fifty (1250) preschool children (657 boys and 593 girls) aged 2.0-6.0 years old from all public municipality kindergartens of Thessaloniki, Greece, participated in this cross-sectional survey conducted from 2009 to 2010. Body weight and height were measured and detailed anthropometry measurement was undertaken. BMI was classified to weight categories based on the CDC (US Centers for Disease Control and Prevention), IOTF (the International Obesity Task Force) and WHO (the World Health Organization) references. RESULTS: Rates of excess body weight varied significantly according to the different international criteria: IOTF: overweight (including obesity) $21.2 \%$, obesity $5.8 \%$; CDC: overweight (including obesity) $30.5 \%$, obesity $13.5 \%$; and WHO: overweight (including obesity) $32.6 \%$, obesity $5 \%$. Boys and older children were particularly affected. CONCLUSIONS: Overweight prevalence is high in Greek preschoolers and varies significantly according to the different criteria used, from $21.2 \%$ (IOTF reference) to $32.6 \%$ (CDC reference).
\end{abstract}

Key words: Anthropometry, BMI, Greek preschoolers, International reference, Obesity

Address for correspondence:

Maria Hassapidou, Department of Nutrition \& Dietetics, Alexander Technological Educational Institute of Thessaloniki, Sindos, 57400, Thessaloniki, Greece; Tel.: +30 2310791591 , E-mail: mnhas@nutr.teithe.gr

Received: 04-11-2014, Accepted: 26-05-2015

\section{INTRODUCTION}

Over the last few decades, the prevalence of childhood obesity has increased dramatically worldwide and in some countries, such as Greece, it has resulted in a major public health issue. ${ }^{1,2}$ Obesity in preschool age 
children is poorly studied compared to school age and adolescence, despite the fact that excess body mass index (BMI) among preschoolers has been identified as a risk factor for obesity in early adulthood. ${ }^{3}$ Existing data support the view that childhood obesity is occurring at even younger ages and primarily when children enter kindergarten. ${ }^{4}$ To the best of our knowledge, only one Greek study, the Genesis study, has investigated excess body weight in preschoolers and reported a high prevalence of overweight. ${ }^{5}$ Cattaneo et $\mathrm{al}^{6}$ reviewed existing data in the European Union and reported that Greek preschoolers demonstrated high overweight and obesity rates, which is in agreement with overweight-obesity trends described in other Mediterranean European countries and the UK.

Overweight in childhood can be determined with accuracy using BMI; however, different criteria for BMI category classification have been developed. The three references most frequently used are: a) the 2000 Centers for Disease Control and Prevention (CDC) charts that classify children and adolescents as overweight at the $85^{\text {th }}$ and $95^{\text {th }}$ percentiles $\left(\geq 85^{\text {th }}\right.$ to $<95^{\text {th }}$ percentile) and obese ( $\geq 95^{\text {th }}$ percentile), which are mainly used in the USA $;^{7}$ b) the International Obesity Task Force (IOTF) which provided gender-specific values from 2 to 18 years of age, corresponding to BMI cut-off limits of adulthood, that is, $25 \mathrm{~kg} / \mathrm{m}^{2}$ for overweight and $30 \mathrm{~kg} / \mathrm{m}^{2}$ for obesity; ${ }^{8}$ and c) the 2007 World Health Organization (WHO) growth curves using BMI $z$ scores +1 and +2 standard deviations (SD) for defining, respectively, overweight and obesity. ${ }^{9}$ The IOTF criteria are now the most frequently used universally for quantifying and comparing the prevalence of overweight and obesity between different populations.

Besides BMI, waist-to-height ratio (WHtR) has recently emerged as an important index for defining abdominal obesity (AO) and high cardiometabolic risk, with a WHtR exceeding 0.5 having been proposed to be pathological in both children and adults. ${ }^{10}$

Anthropometry is an important tool for individual assessment as well as for planning at population level and provides important anthropometric data that reflect children's general health, nutritional status and physical development. ${ }^{11}$ There is now a consensus that indicators based on weight and height measurements should be used for early identification of weight gain in children. ${ }^{12} \mathrm{An}$ anthropometric reference for international use was released by the $\mathrm{WHO}^{13}$ and data for the US population based on the 1999-2002 NHANES survey ${ }^{14}$ were reported and used for estimating obesity trends in young children.

The primary objective of the present cross-sectional study was to assess overweight and obesity status in a sample of preschoolers 2-6 years old in Thessaloniki, the second largest city in Greece after Athens. Secondly, comparison between prevalence estimates for overweight-obesity using three sets of growth references, namely the IOTF, WHO and CDC, was undertaken.

\section{METHODS}

\section{Population sample}

The study was carried out in all (nineteen) public nurseries of the Municipality of Thessaloniki, Northern Greece, during the school year from September 2009 to June 2010. Undersigned approval was obtained from the Greek Ministry of Health and the Prefecture medical officer. All parents/caregivers of participants signed a written informed consent form prior to the implementation of the study procedures.

The Alexander Technological Educational Institute's Ethics Committee approved the study design and implementation. The study was conducted according to the Helsinki Declaration. The sample analyzed consisted of 1006 preschool children, 529 boys and 477 girls, aged 2.0-6.0 years old (mean age 3.94 \pm 0.87 years). The initial number of all children in the kindergartens was 1250 children (657 boys, 593 girls). The participation rate, including valid provided data, was $80.5 \%$ of the initial sample.

\section{Anthropometry}

Anthropometric measurements were taken according to the WHO Multicentre Growth Reference Study Group. ${ }^{15}$ Body weight measurement was performed using an electronic scale (Seca 813, Germany) to the nearest $100 \mathrm{~g}$. Height was measured to the nearest 0.5 $\mathrm{cm}$ using a portable stadiometer (Charder, Taiwan). For mid-upper arm (MUAC) (measured at the mid-point of the olecranon and acromium) and waist circumference (WC) (measured at midway between the iliac 
crest and the lowest border of the rib cage), a wide flat plastic tape strip was used. ${ }^{12}$ Lange calipers (Beta Technology Inc, Santa Cruz) were used for the triceps (Ts) skinfold, measured at the midpoint between the acromion and the olecranon, the subscapular (Ss) skinfold, measured at $1 \mathrm{~cm}$ below the inferior angle of the scapula, and the suprailiac (SIs) skinfold, measured $1 \mathrm{~cm}$ over the iliac crest at the midaxillary line. Body fat percentage $(\mathrm{BF} \%)$ was calculated using Slaughter equations. ${ }^{16}$ All measurements were taken three times and an average value was recorded. Circumferences and skinfolds were measured on the left side of the body. BMI and WHtR were also calculated. WHtR $>0.5$ was considered elevated and identified children as abdominally obese. ${ }^{10}$

Overweight and obesity status was calculated using the IOTF, ${ }^{8} \mathrm{WHO}^{9}$ and $\mathrm{CDC}$ criteria. ${ }^{7}$ Epi Info software v 3.5.1, developed by CDC, was used for the calculation of all percentiles. AnthroPlus software v 3.0.1, delivered by the WHO, was used for the calculation of $\mathrm{z}$ scores according to the WHO growth charts.

\section{Statistical analysis}

Statistical analysis was performed using SPSS v.17 software (SPSS Inc, Chicago I11). Continuous and categorical variables are presented as mean $\pm \mathrm{SD}$ and as percentages, respectively. Differences in categorical variables between groups were evaluated with the chi-square test. Differences in continuous variables between groups were evaluated with one-way analysis of variance and post-hoc; pairwise comparisons were performed with the Holm-Sidak test. Statistical significance was set at $\mathrm{p}<0.05$.

\section{RESULTS}

Anthropometric characteristics of preschool children of both sexes, classified into age categories, are depicted in Table 1 and in Figures 1, 2, 3 and 4. Overall, BMI was higher -at the limit of significance $(p=0.052)-$ in boys than in girls. WC and WHtR showed no statistical difference, while BF\% was higher in girls than in boys. As presented in Table 2, an increase in WC and a decrease in WHtR by age categories was observed in both genders ( $\mathrm{p}$ for trend $<0.001$ ), while an increase in $\mathrm{BF} \%$ was found only in girls ( $\mathrm{p}$ for trend $=0.039$ ).

Table 3 shows prevalence of overweight and obesity according to the IOTF, WHO and CDC references. The overall overweight prevalence according to IOTF, WHO and CDC were $21.2 \%, 32.6 \%$ and $30.5 \%$, respectively. Concerning overweight, the rates as per the IOTF criteria were 1.54 and 1.44 times significantly lower compared to these of the WHO $(\mathrm{p}<0.001)$ and $\mathrm{CDC}(\mathrm{p}<0.001)$, respectively. CDC overweight percentage was 1.07 times significantly lower compared to WHO $(\mathrm{p}<0.001)$. Obesity rates derived from the IOTF, WHO and CDC references were $5.8 \%, 5 \%$ and $13.5 \%$, respectively. CDC demonstrated 2.33 and 2.70 times significantly higher obesity prevalence compared to IOTF $(\mathrm{p}<0.001)$ and WHO $(\mathrm{p}<0.001)$, respectively.

Table 1. Comparison of anthropometric parameters between genders in each age category

\begin{tabular}{|c|c|c|c|c|c|c|c|c|c|c|c|c|}
\hline \multirow{2}{*}{$\begin{array}{l}\text { Age } \\
\text { groups }\end{array}$} & \multicolumn{3}{|c|}{ Body mass index $\left(\mathrm{kg} / \mathrm{m}^{2}\right)$} & \multicolumn{3}{|c|}{ Waist circumference (cm) } & \multicolumn{3}{|c|}{ Waist-to-height ratio } & \multicolumn{3}{|c|}{ Body fat $\%$} \\
\hline & Boys & Girls & p & Boys & Girls & $\mathbf{p}$ & Boys & Girls & p & Boys & Girls & $\mathbf{p}$ \\
\hline $\begin{array}{l}2-3 \text { years } \\
(n=73)\end{array}$ & $16.32 \pm 1.58$ & $16.45 \pm 1.90$ & 0.756 & $49.73 \pm 3.66$ & $48.46 \pm 3.05$ & 0.123 & $0.55 \pm 0.04$ & $0.53 \pm 0.04$ & 0.237 & $14.28 \pm 3.49$ & $15.43 \pm 3.13$ & 0.152 \\
\hline $\begin{array}{l}3-4 \text { years } \\
(n=292)\end{array}$ & $16.50 \pm 1.68$ & $16.03 \pm 1.93$ & 0.029 & $50.75 \pm 3.66$ & $50.09 \pm 3.12$ & 0.104 & $0.51 \pm 0.04$ & $0.52 \pm 0.03$ & 0.258 & $14.32 \pm 3.75$ & $14.81 \pm 3.04$ & 0.226 \\
\hline $\begin{array}{l}4-5 \text { years } \\
(n=404)\end{array}$ & $16.63 \pm 1.78$ & $16.35 \pm 1.69$ & 0.095 & $52.71 \pm 4.10$ & $52.10 \pm 3.95$ & 0.130 & $0.50 \pm 0.03$ & $0.50 \pm 0.03$ & 0.364 & $14.23 \pm 4.25$ & $15.83 \pm 4.12$ & $<0.001$ \\
\hline $\begin{array}{l}5-6 \text { years } \\
(n=246)\end{array}$ & $16.38 \pm 2.05$ & $16.42 \pm 2.25$ & 0.904 & $53.13 \pm 4.41$ & $53.39 \pm 5.04$ & 0.672 & $0.48 \pm 0.04$ & $0.49 \pm 0.04$ & 0.375 & $14.59 \pm 4.58$ & $16.13 \pm 4.48$ & 0.010 \\
\hline $\begin{array}{l}\text { Overall } \\
(n=1006)\end{array}$ & $16.51 \pm 1.80$ & $16.28 \pm 1.91$ & 0.052 & $51.98 \pm 4.18$ & $51.61 \pm 4.23$ & 0.163 & $0.50 \pm 0.04$ & $0.50 \pm 0.04$ & 0.785 & $14.35 \pm 4.13$ & $15.59 \pm 3.91$ & $<0.001$ \\
\hline
\end{tabular}

$\mathrm{p}<0.05$ for statistical significant difference. 


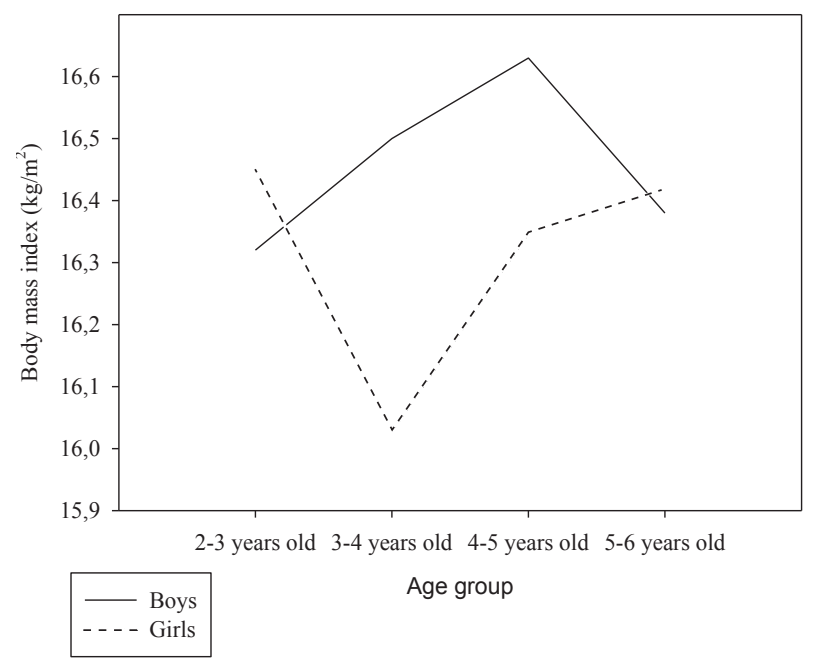

Figure 1. Mean body mass index according to gender and age category.

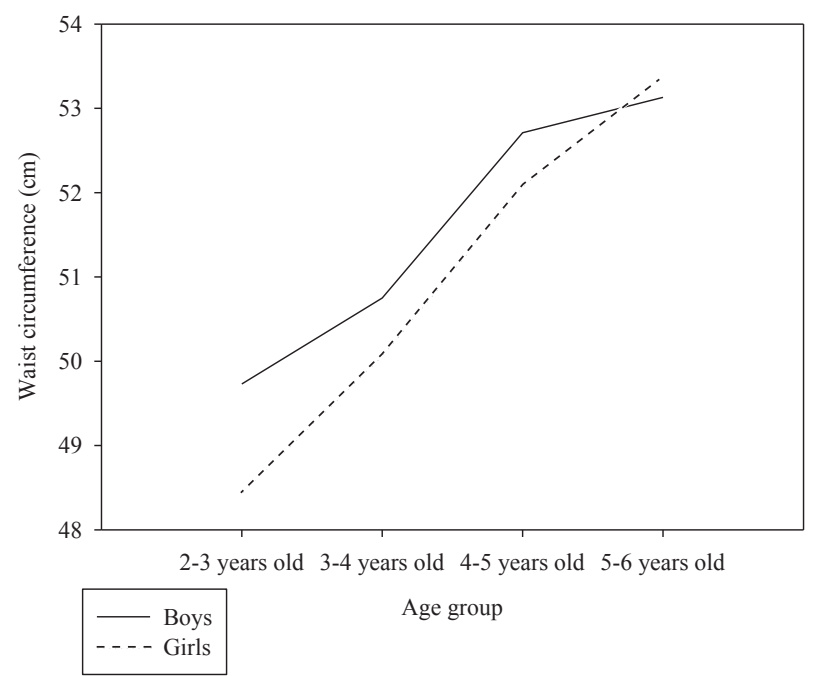

Figure 2. Mean waist circumference according to gender and age category.

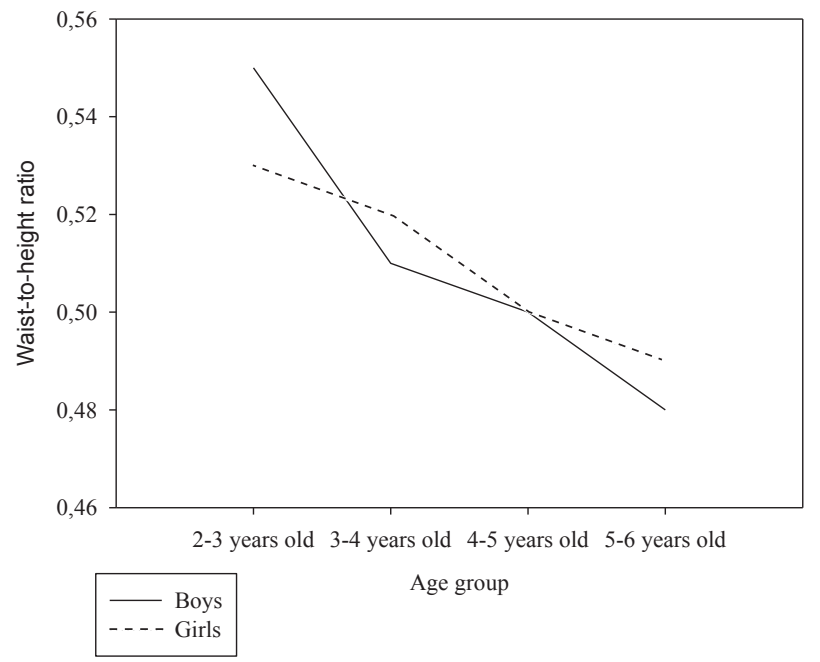

Figure 3. Mean waist-to-height ratio according to gender and age category.

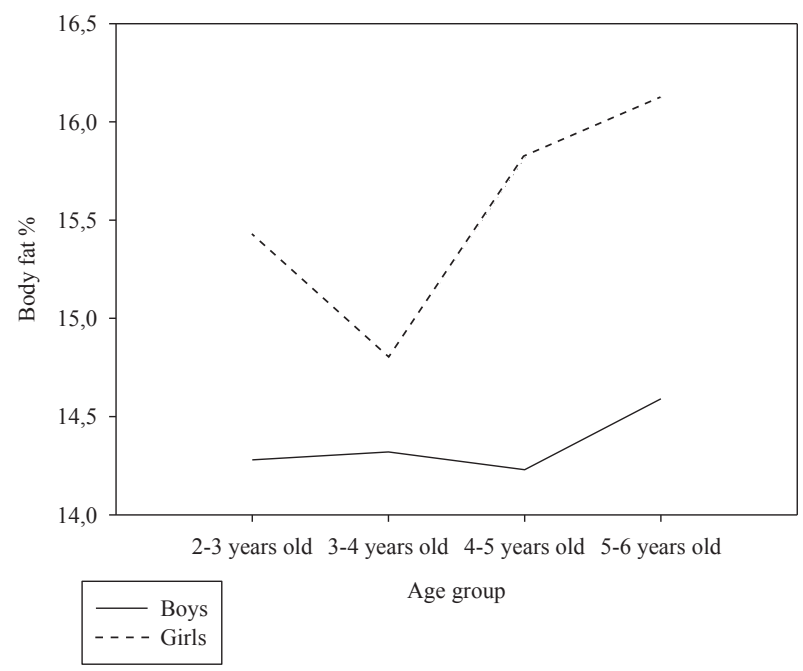

Figure 4. Mean body fat $\%$ according to gender and age category.

Table 2. Differences in anthropometric parameters between age groups in boys and girls

\begin{tabular}{|c|c|c|c|c|c|c|c|c|}
\hline & \multirow{2}{*}{\multicolumn{2}{|c|}{$\begin{array}{l}\mathrm{p} \text { for trend } \\
\text { for the comparison } \\
\text { between age groups }\end{array}$}} & \multicolumn{6}{|c|}{ Pairwise comparisons between age groups } \\
\hline & & & \multicolumn{2}{|c|}{$2-3$ vs. $3-4$ years } & \multicolumn{2}{|c|}{ 3-4 vs. $4-5$ years } & \multicolumn{2}{|c|}{$4-5$ vs. 5-6 years } \\
\hline & Boys & Girls & Boys & Girls & Boys & Girls & Boys & Girls \\
\hline Body mass index & 0.567 & 0.352 & 0.994 & 0.861 & 0.980 & 0.609 & 0.781 & 1.000 \\
\hline Waist circumference & $<0.001$ & $<0.001$ & 0.600 & 0.232 & $<0.001$ & $<0.001$ & 0.934 & 0.038 \\
\hline Waist-to-height ratio & $<0.001$ & $<0.001$ & $<0.001$ & 0.137 & 0.018 & $<0.001$ & 0.001 & 0.247 \\
\hline Body fat $\%$ & 0.893 & 0.039 & 1.000 & 0.964 & 1.000 & 0.109 & 0.971 & 0.985 \\
\hline
\end{tabular}

$\mathrm{p}<0.05$ for statistical significant difference. 
Table 3. Prevalence of overweight (including obesity) and obesity according to the US Centers for Disease control and Prevention (CDC), International Obesity Task Force (IOTF) and World Health Organization (WHO) criteria in boys and girls and in the different age groups

\begin{tabular}{|c|c|c|c|c|c|c|c|c|c|c|c|c|}
\hline & \multicolumn{6}{|c|}{ Prevalence of overweight (including obesity)(\%) } & \multicolumn{6}{|c|}{ Prevalence of obesity (\%) } \\
\hline & \multicolumn{2}{|c|}{ IOTF criteria } & \multicolumn{2}{|c|}{ WHO criteria } & \multicolumn{2}{|c|}{ CDC criteria } & \multicolumn{2}{|c|}{ IOTF criteria } & \multicolumn{2}{|c|}{ WHO criteria } & \multicolumn{2}{|c|}{ CDC criteria } \\
\hline & Boys & Girls & Boys & Girls & Boys & Girls & Boys & Girls & Boys & Girls & Boys & Girls \\
\hline $2-3$ years old $(n=43)$ & 20.9 & 20.0 & $25.6^{*}$ & 36.7 & 18.6 & 16.7 & 0.0 & 3.3 & 4.7 & 3.3 & 4.7 & 3.3 \\
\hline 3-4 years old $(\mathrm{n}=158)$ & $17.1^{*}$ & 11.9 & $22.8^{*}$ & 30.6 & $25.9^{*}$ & 21.6 & $3.8^{*}$ & 1.5 & $2.5^{*}$ & 0.7 & $12.0^{* *}$ & 6.7 \\
\hline $4-5$ years old $(n=203)$ & 23.6 & 22.9 & $44.3^{*}$ & 36.3 & 38.4 & 35.3 & 7.4 & 6.0 & $14.3^{* *}$ & 2.5 & $20.7 * *$ & 13.9 \\
\hline $5-6$ years old $(n=125)$ & 25.6 & 25.9 & 27.2 & 28.6 & 31.2 & 32.1 & 9.6 & 8.9 & 2.4 & 4.5 & $17.6^{* *}$ & 11.6 \\
\hline Total $(\mathrm{n}=529)$ & $21.9^{*}$ & 20.3 & 32.3 & 32.9 & $31.4 *$ & 29.6 & $6.2 *$ & 5.2 & $7.2^{* *}$ & 2.5 & $16.1^{* *}$ & 10.7 \\
\hline Both sexes ( $\mathrm{n}=1006)$ & \multicolumn{2}{|c|}{21.2} & \multicolumn{2}{|c|}{32.6} & \multicolumn{2}{|c|}{30.5} & \multicolumn{2}{|c|}{5.8} & \multicolumn{2}{|c|}{5.0} & \multicolumn{2}{|c|}{13.5} \\
\hline
\end{tabular}

$* \mathrm{p}<0.05$ and $* * \mathrm{p}<0.01$ for comparison of prevalence of overweight and obesity between boys and girls of same age-groups.

Significantly higher prevalence of overweight was demonstrated for boys compared to girls using IOTF and CDC $(\mathrm{p}<0.001)$. Obesity rates were significantly higher in boys compared to girls according to all international criteria $(p<0.001)$. Finally, based on the WHtR index, 239 boys (45.2\%) and 207 girls (43.4\%) were found to be abdominally obese (WHtR $>0.5)$. In figures 5, 6 and 7, age and gender-specific prevalence of overweight and obesity prevalence based on three international criteria is presented.

\section{DISCUSSION}

The present study conducted in Thessaloniki, the second largest city in Greece, confirmed that the prevalence of overweight and obesity appears to be high in preschool children and varies according to the criteria used i.e. $21.2 \%$ according to IOTF, $32.6 \%$ as

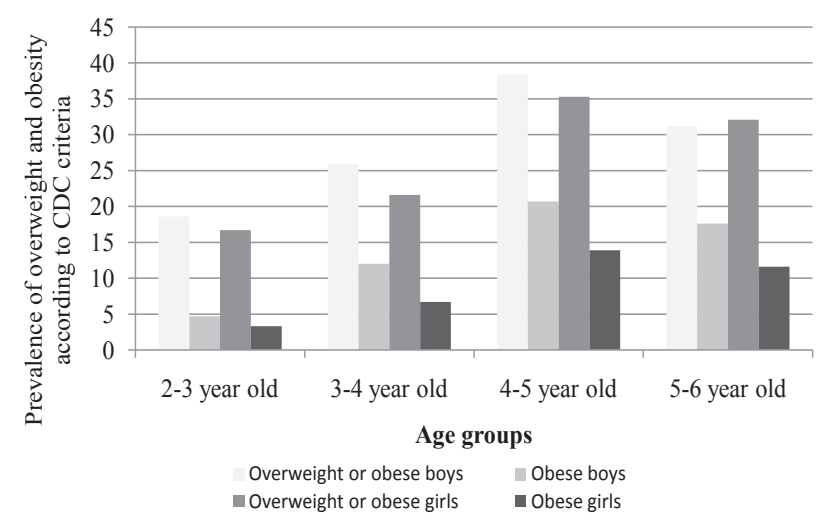

Figure 5. Prevalence of overweight according to gender and age group based on the Centers for the Disease Control and Prevention (CDC) criteria. defined by the WHO reference and $30.5 \%$ by the CDC reference. Obesity rates were found to be $5.8 \%, 5 \%$ and $13.5 \%$ for IOTF, WHO and CDC, respectively.

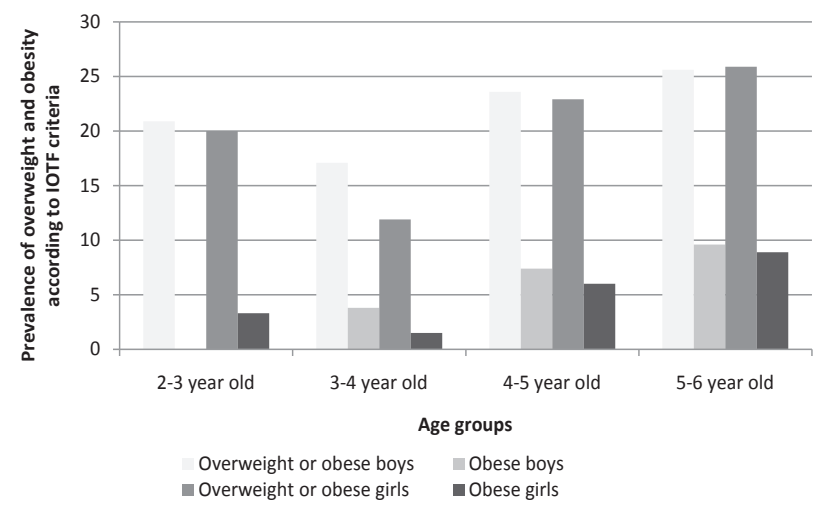

Figure 6. Prevalence of overweight and obesity according to gender and age group based on the International Obesity Task Force (IOTF) criteria.

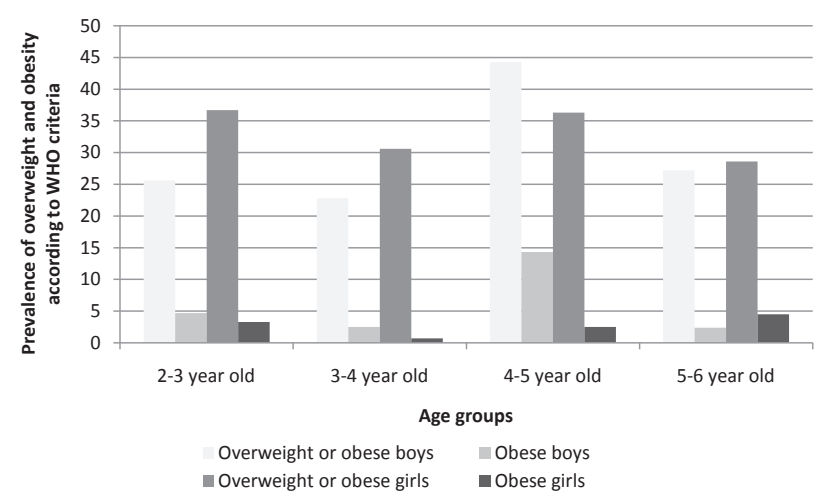

Figure 7. Prevalence of overweight and obesity according to gender and age group based on the World Health Organization (WHO) criteria. 
In Greece, obesity is a major health issue, affecting all age groups of both genders. ${ }^{2}$ This epidemic phenomenon seems to notably affect preschool children. Only one study, however, the GENESIS study, has previously investigated obesity prevalence in preschoolers in Greece. ${ }^{5}$ This study, which was conducted in 2003-2004 and included children aged 1-5 years old from the whole country, showed high prevalence of overweight, varying from $21.3 \%$ (IOTF criteria) to $31.9 \%$ (CDC criteria). Interestingly, these rates are fairly comparable to those found in our regional study, conducted six years after the GENESIS study, and illustrate the severity of the problem, even from very young ages. It is encouraging that there appears to have been no significant increase in excess body weight in preschoolers from 2003-04 to 2009-10, although no direct comparisons can be made between the two studies. Concerning age, WC and WHtR, but not BMI, were found to have increased by the different age-groups in both genders, while estimation of body fat increased significantly by age only in girls. This finding indicates that the adiposity rebound occurs at an earlier age in girls than in boys. ${ }^{17}$ Noticeably, some other gender differences emerged from our regional study. Significantly, many more boys than girls were classified in the obese category and this applied for most age-groups. Overweight prevalence was also higher for boys using the IOTF and CDC criteria, while when using the WHO cut-offs both genders were equally affected. In most European countries, overweight rates in girls tend to be higher than those in boys when the IOTF cut-offs are used, but not when the WHO standards are used. ${ }^{6}$ Similarly, in the GENESIS study, excess body weight was more pronounced in girls than in boys. ${ }^{5}$ However, the last NHANES study, which provided measured representative data among US children and adolescents in 2009-2010 using the CDC criteria, revealed in the 2-5y age-group higher rates of overweight and obesity in boys than in girls. ${ }^{18}$ Based on these data, we believe that no definite conclusions can be drawn in terms of gender differences.

The review of the existing data by Cattaneo et $\mathrm{al}^{6}$ in 2010 synthesized all available information on the prevalence of overweight and obesity in preschool children in the European Union. The authors concluded that countries in the Mediterranean region and the
British Isles had higher rates than those in Central, Northern and Eastern Europe. Indeed, the rates of overweight in the present study are fairly similar to those of other Mediterranean countries reported in the above mentioned review. ${ }^{6}$ It would be of interest to compare our results with those of other urban European areas as well. For example, a study carried out in the city of Leeds, UK, using a British reference data set, the proportions of preschool children who were overweight were at $18 \%$ and that of obesity at $6.6 \%$, which indicates similar trends to our study. ${ }^{19}$

When comparing our results with more recent studies from countries using the same IOTF criteria, we found similar rates of overweight (including obesity) to those of Italy $-21.2 \%$ in both countries- but significantly higher rates than those of Poland (17.1\%) and Denmark (14.6\%). ${ }^{20}$ Interestingly, the latest NHANES study in the USA, which was conducted during the same timeframe as our study, showed in the 2-5y agegroup prevalence of overweight (including obesity) at $26.7 \%$ and obesity at $12.1 \%$ in both sexes using the CDC criteria. ${ }^{18}$ These rates are lower than those reported in our study, which are $30.5 \%$ for overweight (obesity) and $13.5 \%$ for obesity.

In preschoolers, several growth charts were developed internationally because of important ethnic differences and adiposity changes. ${ }^{9}$ The IOTF reference is based on children from cross-sectional surveys designed to be representative of the whole population, the WHO standard is based on a sample of healthy children selected to represent optimal growth and the CDC shows normal growth in children from US national survey data. ${ }^{9,21}$ These three international methods that are most frequently used to define overweight and obesity based on BMI cut-off points generate, however, markedly different results. In accordance with previous studies, ${ }^{9,21}$ our current results showed that in the overweight category the IOTF cut-off points produced the lowest estimates and the WHO the highest, while the CDC cut-points tended to be lower than those of the WHO, particularly in boys. The reason for these discrepancies is that the WHO curve at +1SD is a much lower cut-off point compared to the other two criteria and therefore increases the prevalence of those classified as overweight. ${ }^{9}$ Two recent studies that were conducted in China and in Canada and that used all three criteria 
reported comparable outcomes. ${ }^{22,23}$ It should also be emphasized that differences between the IOTF and WHO estimates tend to be more pronounced in boys than in girls, a finding that was also reported in the Canadian study. ${ }^{21,23}$ In the obese category of the present study, CDC estimates were significantly higher compared to IOTF and WHO, respectively, whilst the WHO and IOTF criteria showed similar rates. The higher obesity estimates found with the CDC criteria could result from the fact that the cut-off limits by the WHO (2SD above the mean) are higher than those of the CDC (95th percentile) for defining obesity. ${ }^{9}$ Concerning the IOTF values, sensitivity and specificity for defining obesity is lower than for defining overweight. ${ }^{21}$

Inadequate breastfeeding ${ }^{2}$ and the parental $\mathrm{BMI}^{5}$ are possible causes of increased body weight in preschoolers in Greece. Other lifestyle factors like overweight at an early age, maternal educational level, race/ ethnicity and hours of television viewing could also play a role, as already indicated in similar studies. ${ }^{24-26}$

The present study was conducted during the biennium 2009-2010, just at the beginning of the economic crisis. Thus, overweight and obesity in preschoolers may have worsened due to reduced financial circumstances of households, which could lead to increased purchase of low-cost, processed, high-fat food and consequently to poor nutrition and health. ${ }^{27}$ Previous studies have suggested that the economic recession has resulted in reduced access to a nutritious diet and impaired nutritional status and health. ${ }^{28,29}$ Whether the current financial crisis in Greece has had a deteriorating effect on the obesity prevalence merits further investigation in future studies.

Limitations of the study are the cross-sectional design and the lack of data on associated factors that would enable us to draw conclusions on possible causes and effects. Furthermore, this is a study in a big urban city of Greece and conclusions on the results cannot be generalized for the whole country. Finally we used skinfolds measurement for evaluation of $\mathrm{BF} \%$, which seems to be a less accurate method than others (e.g. bioelectrical impedance analysis) in this particular pediatric population..$^{30}$ In addition, estimating total body fatness using Slaughter equations has not been validated for preschool children but only for older children. ${ }^{31}$ For these reasons we did not focus our discussion on these anthropometric parameters but purely provided relevant data. On the other hand, important strengths of our study are the inclusion of all public municipal kindergartens of the city in the sample and the high participation rate.

\section{CONCLUSIONS}

Overweight (including obesity) prevalence in Northern Greece preschoolers was found to be elevated, though it varied significantly according to the different criteria used, i.e. ranging from $21.2 \%$ (IOTF) to $32.6 \%$ (CDC). Overweight and obesity were found to be predominant among boys and older children. Concerning the references used, overweight rates were similarly defined by the WHO and CDC criteria, while CDC seemed to overestimate obesity. The variations on overweight and obesity estimation using the IOTF, WHO and CDC criteria indicate the need for a detailed validation of these tools, especially when preschool children are being measured.

\section{REFERENCES}

1. Tzotzas T, Krassas GE, 2004 Prevalence and trends of obesity in children and adults of South Europe. Pediatr Endocrinol Rev 1: Suppl 33: 448-454.

2. Roditis ML, Parlapani ES, Tzotzas T, Hassapidou M, Krassas GE, 2009 Epidemiology and predisposing factors of obesity in Greece: From the Second World War until today. J Pediatr Endocrinol Metab 22: 389-405.

3. Whitaker R, Pepe M, Wright J, Seidel KD, Dietz WH, 1998 Early adiposity rebound and the risk of adult obesity. Pediatrics 101: 123-130.

4. Cummingham SA, Kramer MR, Nrayan KMV, 2014 Incidence of childhood obesity in the United States. N Engl J Med 370: 403-411.

5. Manios Y, Costarelli V, Kolotourou M, Kondakis K, Tzavara C, Moschonis G, 2007 Prevalence of obesity in preschool children, in relation to parental characteristics and region of residence. Public Health 7: 178-183.

6. Cattaneo A, Monasta L, Stamatakis E, et al, 2010 Overweight and obesity in infants and preschool children in the European Union: a review of existing data. Obesity Rev 11: 389-398.

7. Kuczmarski RJ, Ogden CL, Grumeri Strawn LM, et al, 2000 CDC growth charts: United States. Adv Data 8: $1-27$.

8. Cole TJ, Bellizzi MC, Flegal KM, Dietz WH, 2000 Establishing a standard definition for child overweight and obesity worldwide: international survey. BMJ 320: 1240-1243. 
9. James WPT, Lobstein T, 2009 BMI screening and surveillance: An International Perspective. Pediatrics 124: Suppl 1: 42-49.

10. Maffeis C, Banzato C, Talamini G, 2008 Waist-height ratio, a useful index to identify high metabolic risk in overweight children. J Pediatr 152: 207-213.

11. National Health and Nutrition Examination Survey (NHANES). Anthropometry Procedures Manual. January 2007. Available at: http://www.cdc.gov/nchs/data/ nhanes/nhanes_07_08/manual_an.pdf

12. De Onis M, Onyango AW, Den Broeck JV, Chumlea WC, Martorell L, 2004 Measurement standardization protocols for anthropometry used in the construction of a new international growth reference. Food Nutr Bull 25: Suppl 1: 27-S36.

13. De Onis M, Habicht JP, 1996 Anthropometric reference data for international use: recommendations from a World Health Organization Expert Committee. Am J Clin Nutr 64: 650-658.

14. McDowell MA, Fryar CD, Hirsch E, Ogden CL, 2005 Anthropometric reference data for children and adults: US population, 1999-2002. Adv Data 361: 1-32.

15. De Onis M, Garza C, Victoria CG, Bhan M, Norum KR, 2004 The WHO Multicentre Growth Reference Study (MGRS): Rationale, planning and Implementation. Food Nutr Bull 73: 1086-1093.

16. Slaughter M, Lohman T, Boileau R, et al, 1988 Skinfold equations for estimation of body fatness in children and youth. Hum Biol 60: 709-723.

17. Boonpleng W, Park CG, Gallo AM, 2012 Timing of adiposity rebound: a step toward preventing obesity. Pediatr Nurs 38: 37-42.

18. Ogden CL, Caroll MD, Kit BK, Flegal KM, 2012 Prevalence of obesity and trends in body mass index among US children and adolescents, 1999-2010. JAMA 307: 483-490.

19. Edwards KL, Clarke GP, Ransley JK, Cade JE, 2011 Serial cross-sectional analysis of prevalence of overweight and obese children between 1998 and 2003 in Leeds, UK, using routinely mesure data. Public Health Nutr 14: 56-61.
20. Caroli M, Malerca-Tendera E, Epifani S, et al, 2011 Physical activity and play in kindergarten age children. Int J Pediatr Obes 6: Suppl 2: 47-53.

21. Monasta L, Lobstein T, Cole TJ, Vignerova J, Cattaneo A, 2011 Defining overweight and obesity in preschool children: IOTF reference or WHO standard? Obes Rev 12: 295-300.

22. Shan XY, Xi B, Cheng H, Hou DQ, Wang Y, Mi J, 2010 Prevalence and behavioural risk factors of overweight and obesity among children aged 2-18 in Beijing, China. Int J Pediatr Obes 5: 383-389.

23. Shields M, Tremblay MS, 2010 Canadian childhood obesity estimates based on WHO, IOTF and CDC cut points. Int J Pediatr Obes 5: 265-273.

24. Jouret B, Ahluwalia N, Cristini C, et al, 2007 Factors associated with overweight in preschool-age children in southwestern France. Am J Clin Nutr 85: 1643-1649.

25. Flores G, Lin H, 2013 Factors predicting overweight in US kindergartners. Am J Clin Nutr 97: 1178-1187.

26. Rossem L, Hafkamp-de Groen E, Jaddoe VWV, et al, 2014 The role of early life factors in the development of ethnic differences in growth and overweight in preschool children: a prospective birth cohort. BMC Public Health 14: 722.

27. Drewnowski A, Specter SE, 2004 Poverty and obesity: the role of energy density and energy costs. Am J Clin Nutr 79: 6-16.

28. Brinkman HJ, de Pee Saskia, Sanogo I, Subran L, Bloem MW, 2010 High food prices and the global financial crisis have reduced access to nutritious food and worsened nutritional status and health. Am Inst Nutr 140: 1535-1451.

29. Wang Y, Lim H, 2012 The global childhood obesity epidemic and the association between socio-economic status and childhood obesity. Int Rev Psych 24: 176-188.

30. Reilly JJ, Wilson J, Durnin JV, 1995 Determination of body composition from skinfold thickness: a validation study. Arch Dis Child 73: 305-310.

31. Silva AM, Fields DA, Sardinha LB, Strauss JB, 2013 Body composition: assessment, regulation, and emerging techniques. J Obes 2013: 125068. 